\author{
Abstracta Iranica \\ Abstracta Iranica Revue bibliographique pour le domaine irano-aryen \\ Volume 37-38-39 | 2018 \\ Comptes rendus des publications de 2014-2016
}

\title{
Devin DeWeese, « Islamization in the Mongol Empire »
}

\section{Denise Aigle}

\section{OpenEdition}

1 Journals

\section{Édition électronique}

URL : http://journals.openedition.org/abstractairanica/46402

DOI : 10.4000/abstractairanica.46402

ISBN : 1961-960X

ISSN : 1961-960X

Éditeur :

CNRS (UMR 7528 Mondes iraniens et indiens), Éditions de l'IFRI

Référence électronique

Denise Aigle, « Devin DeWeese, "Islamization in the Mongol Empire » », Abstracta Iranica [En ligne],

Volume 37-38-39 | 2018, document 3, mis en ligne le 30 décembre 2018, consulté le 02 octobre 2020 URL : http://journals.openedition.org/abstractairanica/46402 ; DOI : https://doi.org/10.4000/ abstractairanica.46402

Ce document a été généré automatiquement le 2 octobre 2020.

Tous droits réservés 


\title{
Devin DeWeese, « Islamization in the Mongol Empire »
}

\author{
Denise Aigle
}

\section{RÉFÉRENCE}

Devin DeWeese, «Islamization in the Mongol Empire » in Nicola Di Cosmo, Allen J. Frank, Peter B. Golden (eds.). The Cambridge History of Inner Asia. The Chinggisid Age. Cambridge : Cambridge University Press, $2015^{2}$, p. 120-134

L'auteur étudie les processus d'islamisation dans l'Iran ilkhanide, la Horde d'Or et le khanat chaghataide. Les Ilkhans régnèrent sur une population largement musulmane et en l'espace d'un quart de siècle, Tegüder Ahmad fut le premier Ilkhan à se convertir. Son règne fut de courte durée et la brève expérience d'Ahmad Tegüder montre que le processus d'islamisation des troupes et des émirs mongols n'était pas suffisamment avancé. Un réalignement des forces s'opéra pendant la décennie suivante, lorsque que Ghazan Khan (r. 1295-1304) annonça sa conversion à l'islam peu de temps après la victoire militaire qui garantit son accession au pouvoir. La plupart des sources attribuent la conversion de Ghazan Khan au cheikh Șadr al-Dīn Ibrāhīm, membre d'une éminente famille soufie du Khorasan, mais elle fut politique. D. DeWeese dit que le récit sur la conversion de Ghazan montre la réticence du jeune souverain et : « reminds us of the convert's firm focus on what he was suppose to do, rather than on what he was supposed to tkink» (p. 124). Enfin, à propos de l'islamisation de la Horde d'Or et du khanat chaghataiide, D. DeWeese (p. 133) écrit : «Islamization must be understood as an incremental processes whose parameters constantly shifted, rather than as a discrete step accomplished once an for all by act of royal conversion or state support $»$. En d'autres termes, il s'agit d'une conception de la conversion très différente par rapport au monde moderne. 


\section{AUTEURS}

DENISE AIGLE

UMR 8167 - Orient et Méditerranée 